\title{
A ONE AND HALF YEARS OLD BABY PRESENTED WITH UROSEPSIS FOLLOWING H/O PYELOPLASTY
}

\author{
MD. ASADUZZAMAN ${ }^{1}$, AKM SHAHADAT HOSSAIN ${ }^{2}$, MD. HAFIZ AL ASAD ${ }^{3}$, MD. MAHFUZUR RAHMAN \\ CHOWDHURY $^{4}$, SELIM MORSHED 5
}

\begin{abstract}
:
We report a case in which a one and half years old baby presented with frequent loose motion 10 month back. For this her parent put her to a physician and diagnosed as a case of PUJ obastruction(left). She underwent A-H pyeloplasty in India for PUJ obstruction on Dec,16. She developed fever with chills \& rigor immediately after removal of $D-J$ stent and referred to $\mathrm{DMCH}$. Open nephrostomy was done in $\mathrm{DMCH}$ on March,17. Antegradenephrostogram showed low lying left kidney with moderate hydronephrosis. Reexploration of left kidney was done on oct,17. Left kidney found baggy and distal ureter found atretic. Resection of distal ureter and ureteroneocystostomy with psoas hitch was done.Post operative period was uneventful.
\end{abstract}

Key words : PUJ obstruction, A-H Pyeloplasty.

Bangladesh J. Urol. 2018; 21(2): 172-174

\section{Introduction:}

Obstruction of the ureteropelvic junction is probably the most common congenital abnormality of the ureter. In children, it is seen more often in boys than in girls $(5: 2$ ratio), but it has recently been discovered that in adults, it is more common in women than in men ${ }^{1}$. In unilateral cases, it is more often on the left than on the right side (5:2 ratio). Bilateral obstruction occurs in $10-15 \%$ of cases and is especially common in infants ${ }^{2}$. The abnormality may occur in several members of the same family, but it shows no clear genetic pattern. Some time It may be associated with vescico-ureteric junction obstruction. The exact cause of obstruction of the ureteropelvic junction often is not clear.

Clinical findings vary depending on the patient's age at diagnosis. Pain and vomiting are the most common symptoms; however, hematuria and urinary infection also may be seen. A few patients have complications such as calculi, trauma to the enlarged kidney, or

1. MS Urology, Final Part Student

2. Professor, Department of Urology, Dhaka Medical College, Dhaka.

3. Assistant Professor, Department of Urology,Dhaka Medical College, Dhaka.

4. Assistant Professor, Department of Urology,Dhaka Medical College, Dhaka.

5. Indoor Medical Officer, Department of Urology,Dhaka Medical College, Dhaka.

Correspondences: Dr. Md. Asaduzzaman, Department of Urology, Dhaka Medical College, Dhaka. E-mail: drasadzaman42@gmail.com Received: 27 December 2017 Accepted: 05 March 2018 (rarely) hypertension. The diagnosis is made most often by sonography. In equivocal cases, diuretic renography or (rarely) antegrade urography with pressure-flow studies is helpful ${ }^{3}$.

Pyeloplasty is the surgical reconstruction or revision of the renal pelvis to drain and decompress the kidney. Most commonly it is performed to treat an uretero-pelvic junction obstruction if residual renal function is adequate.There are different types of pyeloplasty depending on the surgical technique and patterns of incision used. The dismembered type of pyeloplasty(called an Anderson-Hynes pyeloplasty) is the most common type of pyeloplasty.A pyeloplasty can either be done by the robotic, open, or laparoscopic route.

\section{Case Report:}

Prokite Shaha Roy, 1.5 years old, hindu female child came from Rajbari presented with -

frequent loose motion for several times 10 month back. For this problem her parent took her to a physician and diagnosed as a case of left sided hydronephrosis due to PUJ obstruction. For this problem they took the baby to a private hospital in india.

In this hospital consultant urologist did some investigation like, ultrasonogram, DTPA renogram, urine R/E and diagnosed as a case of left sided hydronephrosis due to PUJ obstruction. Intravenous 
urography did not perform there at that time. For this diagnosis she underwent(Laparoscopic)A-H pyeloplasty (left) with ureteric stent in that hospital on 09-01-2017.She was discharged on 15-01-17 with someadvise.

D-J stent was removed in a private hospital in Bangladesh on $7^{\text {th }}$ march, 17 by a consultant urologist but preoperative $X$-ray was not done. Immediately after removal of ureteric stent this baby developed fever with chills \& rigor and reffered to $\mathrm{DMCH}$ for admission with further management. In $\mathrm{DMCH}$ some investigations was done \& diagnosed as a case of pyonephosis (left).Open nephrostomy was done under G/A On $15^{\text {th }}$ march,17. Post operative period was uneventful. Daily output through nephrostomy tube was around $500 \mathrm{ml}$. After 6 weeks of nephrostomy DTPA-renogram was done.

The baby again got admitted into $\mathrm{DMCH}$ on $17^{\text {th }}$ Oct, 17 for definite management. This baby was mildly anaemic, body weight- $9.5 \mathrm{~kg}$. An oblique incision mark was seen in left loin, a bi-channel foley's catheter was seen in left loin connected to a closed drainage system. Kidneys were not palpable.Antegradenephrostogram was done which show Moderate low-lying left kidney with moderate hydronephrosis.

After preoperative preparation reoperation was done on 23th Oct, 17 for failed pyeloplasty. Peroperatively

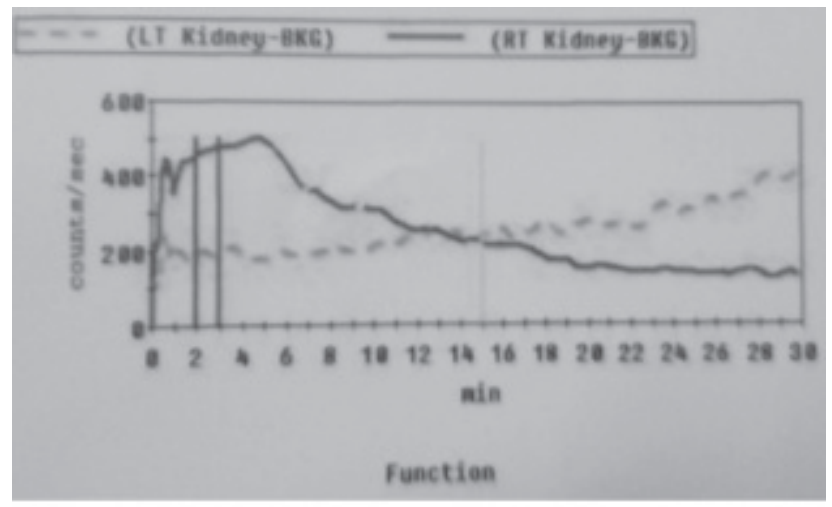

Fig.-1: DTPA -Renogram (07-01-2017)

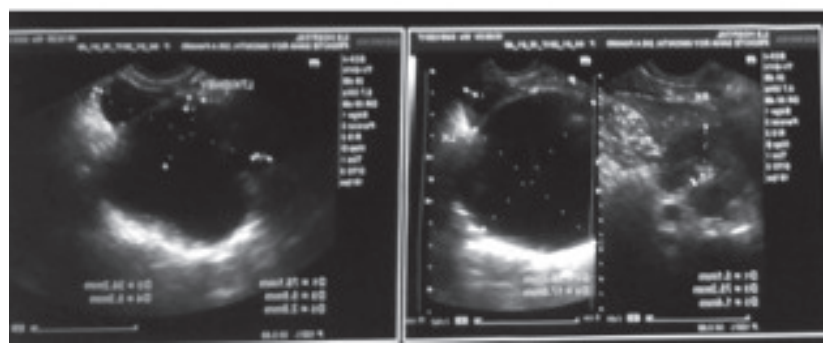

Fig -2: USG of KUB (04-01-2017). pelvis found baggy,upper half of ureter found dilated, lower half of ureter found atreticupto UB. Normal saline was introduce through nephrostomy catheter but saline could not pass through distal ureter. Atretic part of ureter was excised.Ureteroneocystostomy with psoas hitch was done. A $3 \mathrm{fr} D-J$ stent and nephrostomy catheter were kept in situ. Post operative period was uneventful. Stitch off done on $7^{\text {th }}$ POD. Catheter off and clamping of nephrostomy tube was done after 2 weeks. Nephrostomy tube was removed after 3 weeks. Ureteric stent was removed after 8 weeks. Now the baby is well.

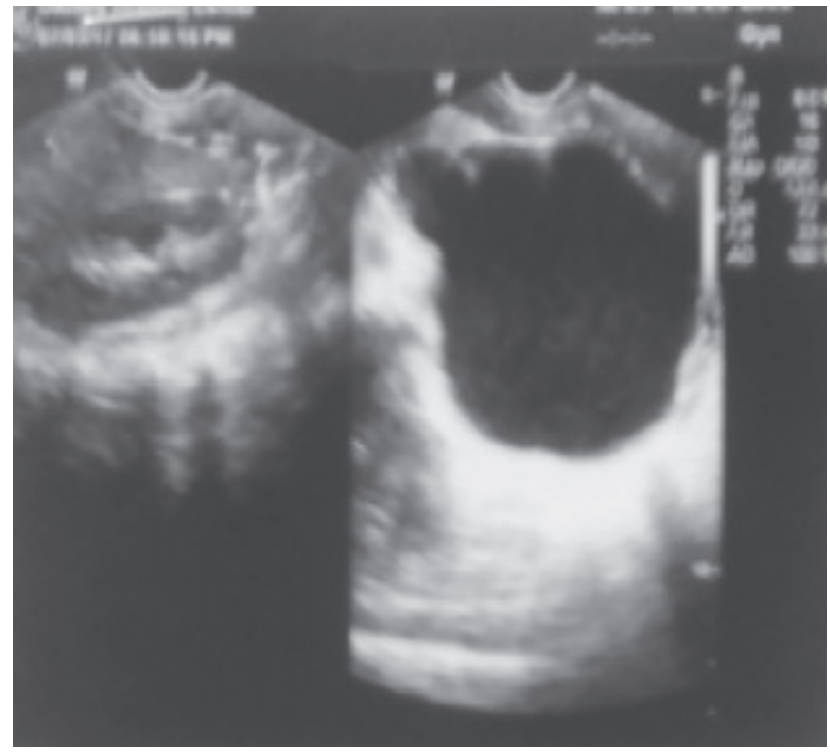

Fig-3 : USG of KUB (15-03-2017).

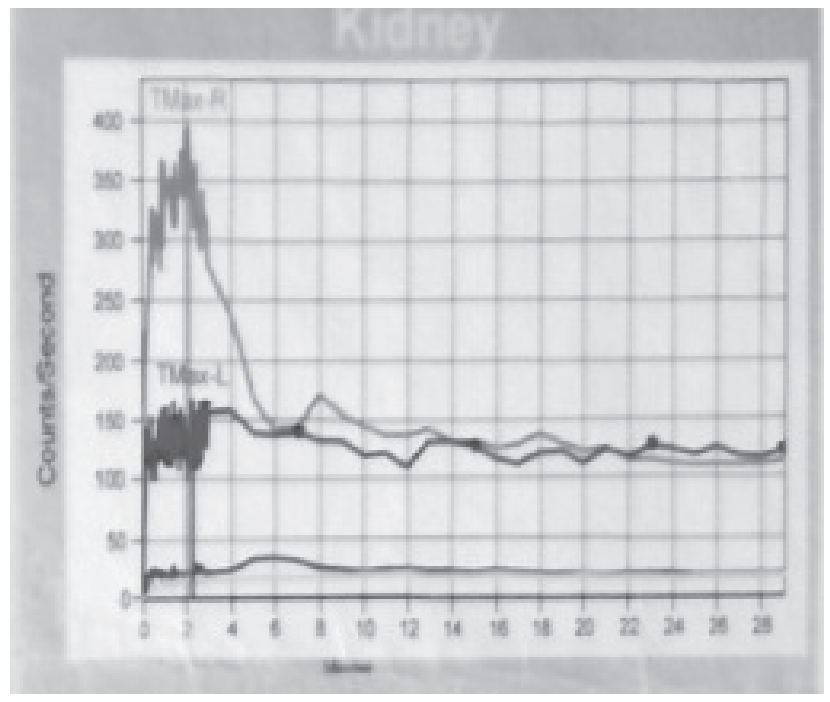

Fig.-4: DTPA -Renogram (02-05-2017) 


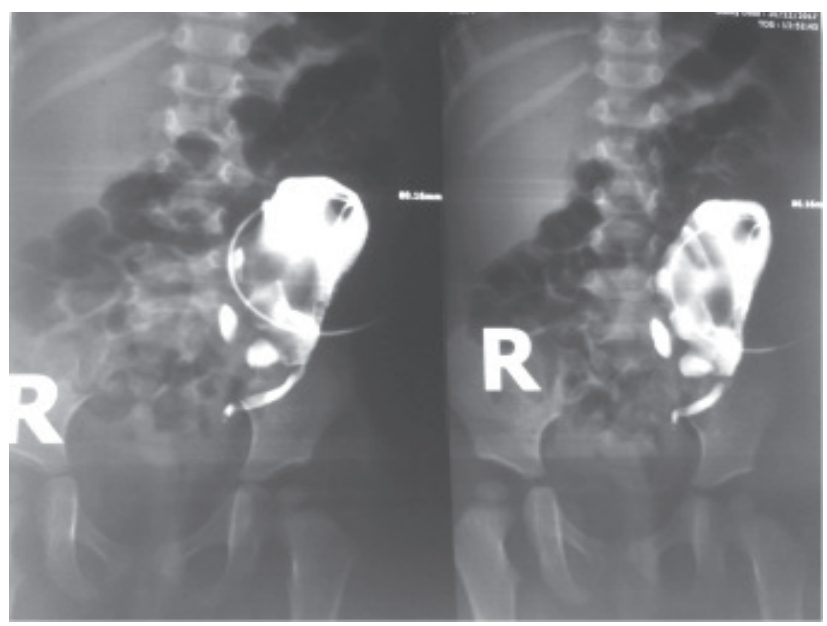

Fig-5 : Antegrade nephrostogram (18 - 10 - 2017)

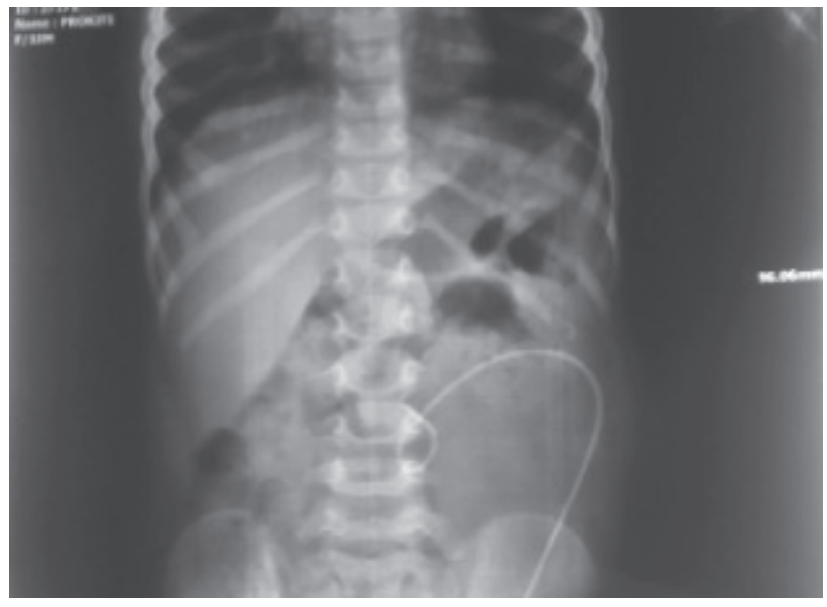

Fig.-6 : Post operative X-ray KUB. (18-11-17)

\section{Discussion:}

Laparoscopic pyeloplasty(LP) for ureteropelvic junction obstruction (UPJO) was first described in $1993^{4}$. Although technically challenging, LP is associated with high success rates, ranging from $84 \%$ to $98 \%$.Given the benefits of easier convalescence, decreased pain, and smaller incisions ${ }^{5-8} \mathrm{LP}$ (both conventional and robot-assisted) is now considered the standard of care for UPJO at many institutions ${ }^{7,9}$. Despite the high success rates, some patients have persistent or recurrent UPJO. Various strategies have been used in these situations: Observation, ureteral stent placement, or percutaneous nephrostomy, EP, repeated LP, OP, or nephrectomy.

In this case UPJ found normal following Pyeloplasty but distal ureter found atretic. Guide wire chould not be negotiated through distal ureter.Ureteroneocystostomy was done after resection of atretic part of ureter.

\section{Conclusion:}

Pyeloplasty is the standard treatment for symptomatic PUJ obstruction.Success rates for the different treatments for ureteropelvic junction (UPJ) obstruction vary depending on a number of factors, including, the degree of obstruction; whether it is a primary or secondary obstruction; the function of the affected kidney; anatomic considerations, such as the presence of crossing vessels; and the expertise of the treating surgeon.More over ,Peroperative RGP should be considered to exclude associated vescico-ureteric junction obstruction.

\section{References:}

1. Capello SA et al: Prenatal ultrasound has led to earlier detection and repair of ureteropelvic junction obstruction. J Urol 2005;174(4, Pt 1): 1425-1428.

2. Johnston $\mathrm{JH}$ : The pathogenesis of hydronephrosis in children. Br J Urol 1969;41(6):724-734.

3. Thrall JH et al: Diuretic radionuclide renography and scintigraphy in the differential diagnosis of hydroureteronephrosis. SeminNucl Med 1981;11(2):89-104.

4. Schuessler WW, Grune MT, Tecuanhuey LV, Preminger GM. Laparoscopic dismembered5. pyeloplasty. J Urol 1993;150:1795-1799.

6. Jarrett TW, Chan DY, Charambura TC, et al. Laparoscopic pyeloplasty: The first 100 cases. J Urol 2002;167:1253-1256.

7. Rassweiler JJ, Subotic S, Feist-Schwenk M, et al. Minimally invasive treatment of ureteropelvic junction obstruction:Long-term experience with an algorithm for laser endopyelotomy and laparoscopic retroperitoneal pyeloplasty. J Urol 2007;177:1000-1005.

8. Moon DA, El-Shazly MA, Chang CM, et al. Laparoscopic pyeloplasty: Evolution of a new gold standard. Urology 2006;67:932-936.

9. Maynes LJ, Levin BM, Webster TM, et al. Measuring the truesuccess of laparoscopic pyeloplasty. J Endourol. 2008;22:1193-1198.

10. Tan BJ, Rastinehad AR, Marcovich R, et al. Trends in ureteropelvic junction obstruction management among urologists in the United States. Urology 2005;65:260-264. 